\title{
Relationships between depressive symptoms and self-reported unintentional injuries: the cross-sectional population-based FIN-D2D survey
}

\author{
Katariina Korniloff1,2*, Arja Häkkinen ${ }^{1,2}$, Hannu J Koponen ${ }^{3,4}$, Hannu Kautiainen ${ }^{5,6}$, Salme Järvenpää7,
} Markku Peltonen ${ }^{8}$, Pekka Mäntyselkä ${ }^{6,9}$, Olli Kampman ${ }^{10}$, Heikki Oksa ${ }^{11}$ and Mauno Vanhala ${ }^{5,9}$

\begin{abstract}
Background: There is a lack of knowledge on the influence of different levels of physical activity (PA) on unintentional injuries among those with depressive symptoms (DS). The aim of this study was to evaluate the relationship between PA categories and unintentional injuries among participants with and without DS based on a cross-sectional population-based FIN-D2D survey conducted in 2007.

Methods: Out of 4500, 2682 participants (60\%) aged 45-74 years attended in this study. The unintentional injuries over the past year were captured in a questionnaire. DS were determined with the Beck Depression Inventory ( $\geq 10$ points) and PA with the International Physical Activity Questionnaire. The statistical significance between DS and unintentional injury categories was evaluated by using $t$-test, chi-square test, or permutation test, analysis of covariance, or regression models. The factors related to unintentional injuries were estimated by univariate and multivariate logistic regression models.

Results: The proportion of subjects with unintentional injuries was higher among those with DS (17\%) compared to those without DS (10\%) (age- and gender-adjusted $p=0.023$ ). The median (range) number of activity-loss days after injury was $22(0-365)$ in participants with DS and $7(0-120)$ in participants without DS $(p=0.009)$. The percentage of subjects with unintentional injuries was not significantly different between PA categories in participants with DS and without DS. A stepwise multivariate logistic regression analysis showed that DS, functional ability, and musculoskeletal diseases were related to unintentional injuries.

Conclusions: PA level was not related to unintentional injuries, whereas those with DS had a higher prevalence of unintentional injuries and prolonged activity-loss after injury. These results underline the importance of injury prevention, especially among those who have DS and additional risk factors.
\end{abstract}

Keywords: Beck depression inventory, Depressive symptoms, Injury, Physical activity

\section{Background}

A sedentary lifestyle is commonly associated with several deleterious health consequences, one of which is depressive symptoms (DS). A number of studies have found DS to be associated with unintentional injury [1-4]. In fact, DS have proved to increase the risk of injury by $41 \%$ [4]. It is also evident that the risk of DS increases

\footnotetext{
* Correspondence: katariina.korniloff@jyu.fi

${ }^{1}$ Department of Health Sciences, University of Jyväskylä, PL 35, Jyväskylä Fl-40014, Finland

${ }^{2}$ Department of Physical and Rehabilitation Medicine, Central Finland Central Hospital, Keskussairaalantie 19, Fl-40620 Jyväskylä, Finland

Full list of author information is available at the end of the article
}

due to unintentional injury [5]. Hence, this phenomenon seems to be bidirectional as demonstrated in a national representative study [2].

Further several socio-demographic factors can be associated with unintentional injuries. These high-risk characteristics are male gender, low income, prior injury, and insufficient night's sleep $[2,4,6]$. Additionally, children, older people, and those who are less educated and have fewer social resources are at highest risk for injuries [7]. Furthermore, an estimated $40-60 \%$ of injuries in Europe may be associated with alcohol consumption [7].

\section{Ciomed Central}

(c) 2012 Korniloff et al.; licensee BioMed Central Ltd. This is an Open Access article distributed under the terms of the Creative Commons Attribution License (http://creativecommons.org/licenses/by/2.0), which permits unrestricted use, distribution, and reproduction in any medium, provided the original work is properly cited. 
Therefore, binge drinking habits among Finns might be remarkable in terms of unintentional injuries [8].

Moreover, behavioral factors like a physically active lifestyle also play a role in the phenomenon of unintentional injuries. Increased physical activity (PA), particularly increased strength and balance training, has proved beneficial in terms of decreasing falling injuries and preventing fractures [9]. Despite several health benefits of PA [10], it may also have some deleterious consequences. Hootman et al. observed that an increased duration of PA per week and a higher cardiorespiratory fitness level were associated with an increased risk of activity-related injury, and that moderate types and duration of PA have lower injury risks than more vigorous types and longer durations of PA [11]. However, a consistent trend was evident when a sedentary lifestyle was compared with a physically active one, with the latter providing some protection against injuries other than activity-related ones [11].

To our knowledge, there is no research concerning the influence of different levels of total PA on unintentional injuries among those with DS. However, the level of PA could decrease as a result of DS. This tendency may then decrease the incidence of activity-related injuries. On the other hand, a sedentary lifestyle is associated with worse functional ability [12,13], which may in turn increase the prevalence of injuries. Thus, the aim of the present cross-sectional population-based study was to describe the relationship between total PA and unintentional injuries among participants with and without DS. An additional aim was to evaluate the prevalence of unintentional injuries in relation to sociodemographic and clinical characteristics as well as functional ability.

\section{Methods}

The Finnish type 2 diabetes (FIN-D2D) population survey was carried out in the hospital districts of Pirkanmaa, Southern Ostrobothnia and Central Finland, between October and December 2007 [14,15]. A random sample of 4500 subjects aged 45-74 years, stratified according to gender, 10-year age groups (45-54, 55-64 and 65-74 years), and the three geographical areas was selected from the National Population Register in August 2007. The study participants were invited by mail to a clinical examination. Of the 4500 persons solicited, 2868 participated in the health examination (attendance $64 \%)$. Non-responders were on average 1.4 years younger than responders $(p<0.001)$, and female were more likely to participate than male $(67 \%$ vs. $61 \%$, $p<0.001)$. After exclusion of 90 subjects because of incomplete information about physical activity, injuries, or DS, the final study group included 2682 (60\%) persons (53\% females) with a mean (SD) age of 59 (8) years. All participants signed an informed consent form. Ethical permission for the study was granted by the Hospital District of Helsinki and the Uusimaa ethics committee.

The health examination methods followed the multinational monitoring of trends and determinants in cardiovascular disease (MONICA) protocol [16], and were made by nurses specially trained in the survey procedures. Height and weight were measured to calculate body mass index (BMI). All participants completed a standard questionnaire including questions about years of education, medications, alcohol use, smoking, physical function, physical activity, and injuries. Information about the participants' chronic diseases during the past 12 months was also captured with questionnaire and categorized into groups of cardiovascular, respiratory, and musculoskeletal diseases.

Alcohol-specific questions inquired about the frequency of times during the past 12 months of drinking alcohol to feel inebriated. Alcohol consumption was classified into four categories as follows: never (0), occasionally (1), at least once a month (2), and at least once a week (3).

Functional ability was evaluated with the modified functional ability questionnaire including questions about dressing, cutting toenails, climbing stairs, walking, carrying, running, cycle and travelling [17-20]. Answers (1, able without difficulties; 2 , able but is difficult; 3 , cannot) were summed in a total score, which accounted for the physical functioning index. For the analysis, the total score was standardized into the scale of $0-10$ with higher numbers indicating worse functioning.

Physical activity (PA) was assessed with the selfadministered short version of the International Physical Activity Questionnaire (IPAQ). This questionnaire estimates the frequency, intensity, and duration of PA during leisure times, at home, and also occupational and commuting physical activity over the previous seven days [21-24]. Total daily PA in MET-min (which is Metabolic Equivalent; $1 \mathrm{MET}=$ resting energy expenditure) was calculated according to the official IPAQ scoring protocol (www.ipaq.ki.se). In the analysis, PA was divided into three categories (low $<600$, moderate 600 2999 , and high $\geq 3000$ ) based on MET-min week ${ }^{-1}$.

The questionnaire asked about unintentional injuries which required medical attention during the past 12 months, and divided them into the following four groups: traffic injuries, home injuries, sports or exercise injuries, and other leisure-time injuries. The questionnaire also asked about the number of activity-loss days, which refers to difficulties coping with daily activities.

DS were assessed with the Beck Depression Inventory (BDI) [25]. The BDI is a 21-item self-report questionnaire consisting of symptoms and attitudes related to depression. The items are summed in a total score that ranges from 0 to 63; higher numbers indicate greater depression. The cut-off point for DS was 10, which 
indicates at least mild depression [26,27]. Participants with DS $\geq 10$ were offered the possibility of meeting with a psychiatrist for further investigation.

\section{Statistical analysis}

The data are presented as means with standard deviations (SD) or as counts with percentages. The most important outcomes are given with 95\% confidence intervals $(\mathrm{CI})$. The comparison between groups was made using $t$-test, chi-square test, or permutation test. When adjusting for confounding factors, analysis of covariance, logistic regression model, or ordered logistic regression model was applied. Univariate logistic regression models and multivariate logistic regression model with forward stepwise selection (probability for entry 0.05 ) were used to investigate factors related to unintentional injuries. Visual assessment of residuals and influence diagnostics were used in validating the assumptions underlying the logistic regression model.

\section{Results}

Three hundred one participants reported at least one unintentional injury during the past 12 months. Table 1 shows the demographic and clinical factors according to unintentional injury status. Participants with unintentional injuries were older, had higher BMI value, higher prevalence of DS, worse functional ability, higher prevalence of cardiovascular, respiratory and musculoskeletal diseases, and greater alcohol use, compared with participants without unintentional injuries.

The prevalence of subjects with unintentional injuries among participants with DS was $17.0 \%$ (95\% CI: $13.5 \%$ to $21.1 \%$ ) and $10.2 \%$ (95\% CI: $9.0 \%$ to $11.5 \%$ ) among participants without DS (age- and genderadjusted $p<0.001$ ). The prevalence of subjects with unintentional injuries among those with low total PA was $10.3 \%$ (95\% CI: $7.7 \%$ to $13.4 \%$ ), among those with moderate PA $10.8 \%$ (95\% CI: $9.1 \%$ to $12.8 \%$ ), and high PA $12.0 \%$ (95\% CI: $10.1 \%$ to $14.1 \%$ ) (age- and sex adjusted $p=0.55$ ). Figure 1 shows main effects and interaction of total PA and DS on unintentional injuries.

A home injury was the most commonly reported injury in both the DS present and not present groups, whereas other leisure time injury was second (Table 2). The mean (range) activity-loss days after injury was 22 $(0-365)$ days in participants with DS and $7(0-120)$ days in participants without DS $(p=0.009)$.

Univariate logistic regression analysis showed that age, BMI, DS, functional ability, and cardiovascular, respiratory and musculoskeletal diseases were significantly related to a higher risk of injuries, but PA level was not. In the forward stepwise multivariate model, the relationship between unintentional injuries and DS, functional
Table 1 Demographic and clinical data according to unintentional injuries

\begin{tabular}{|c|c|c|c|}
\hline & $\begin{array}{l}\text { No } \\
\text { unintentional } \\
\text { injuries } \\
\mathrm{N}=2381\end{array}$ & $\begin{array}{l}\text { Unintentional } \\
\text { injuries } \\
\mathrm{N}=301\end{array}$ & $\begin{array}{l}p- \\
\text { value }^{a}\end{array}$ \\
\hline \multicolumn{4}{|l|}{ Demographic } \\
\hline Female, n (\%) & $1260(53)$ & $153(51)$ & 0.49 \\
\hline Age, mean (SD) & $59.3(8.3)$ & $60.4(8.2)$ & 0.034 \\
\hline Education years, mean (SD) & $11.4(3.6)$ & $11.5(4.2)$ & 0.34 \\
\hline Body mass index, mean (SD) & $27.4(4.8)$ & $38.0(5.5)$ & 0.050 \\
\hline \multicolumn{4}{|l|}{ Clinical } \\
\hline $\begin{array}{l}\text { Depressive symptoms } \\
\text { present, } \mathrm{n}(\%)\end{array}$ & $326(14)$ & $67(22)$ & $<0.001$ \\
\hline Antidepressants, n (\%) & $129(5)$ & $20(7)$ & 0.34 \\
\hline Functional ability, mean (SD) & $0.85(1.33)$ & $1.26(1.77)$ & $<0.001$ \\
\hline Cardiovascular diseases, n (\%) & $820(35)$ & $132(45)$ & 0.005 \\
\hline Respiratory diseases, n (\%) & $187(8)$ & $36(12)$ & 0.026 \\
\hline Musculoskeletal diseases, n (\%) & $698(30)$ & $121(41)$ & $<0.001$ \\
\hline Current smoking, n (\%) & $529(22)$ & $67(22)$ & 0.69 \\
\hline Alcohol use, n (\%) & & & 0.049 \\
\hline Never & $1112(47)$ & $128(43)$ & \\
\hline Occasionally & $841(35)$ & $115(38)$ & \\
\hline At least once a month & $295(12)$ & $39(13)$ & \\
\hline At least once a week & $133(6)$ & $19(6)$ & \\
\hline $\begin{array}{l}\text { Physical activity category } \\
\left(\text { MET min week }{ }^{-1}\right), \mathrm{n}(\%)\end{array}$ & & & 0.28 \\
\hline $\operatorname{Low}(<600)$ & $410(17)$ & $47(16)$ & \\
\hline Moderate (600-2999) & $1019(43)$ & $124(41)$ & \\
\hline High ( $\geq 3000$ ) & $952(40)$ & $130(43)$ & \\
\hline
\end{tabular}

ability, and musculoskeletal diseases remained significant (Table 3).

\section{Discussion}

This population-based survey showed that depressive symptoms (DS) were strongly related to unintentional injuries and that the proportion of subjects with unintentional injuries was almost double among those with DS compared with those without DS. This inequality becomes even more relevant when taking into account that the number of activity-loss days after injury in participants with DS proved to be threefold that of those without DS in this study. However, contrary to our expectation, physical activity level was not related to unintentional injuries among those with or without DS. Since injury prevention has become an important focus of government policy in Finland, it would be worthwhile to draw attention to the various factors behind home and 


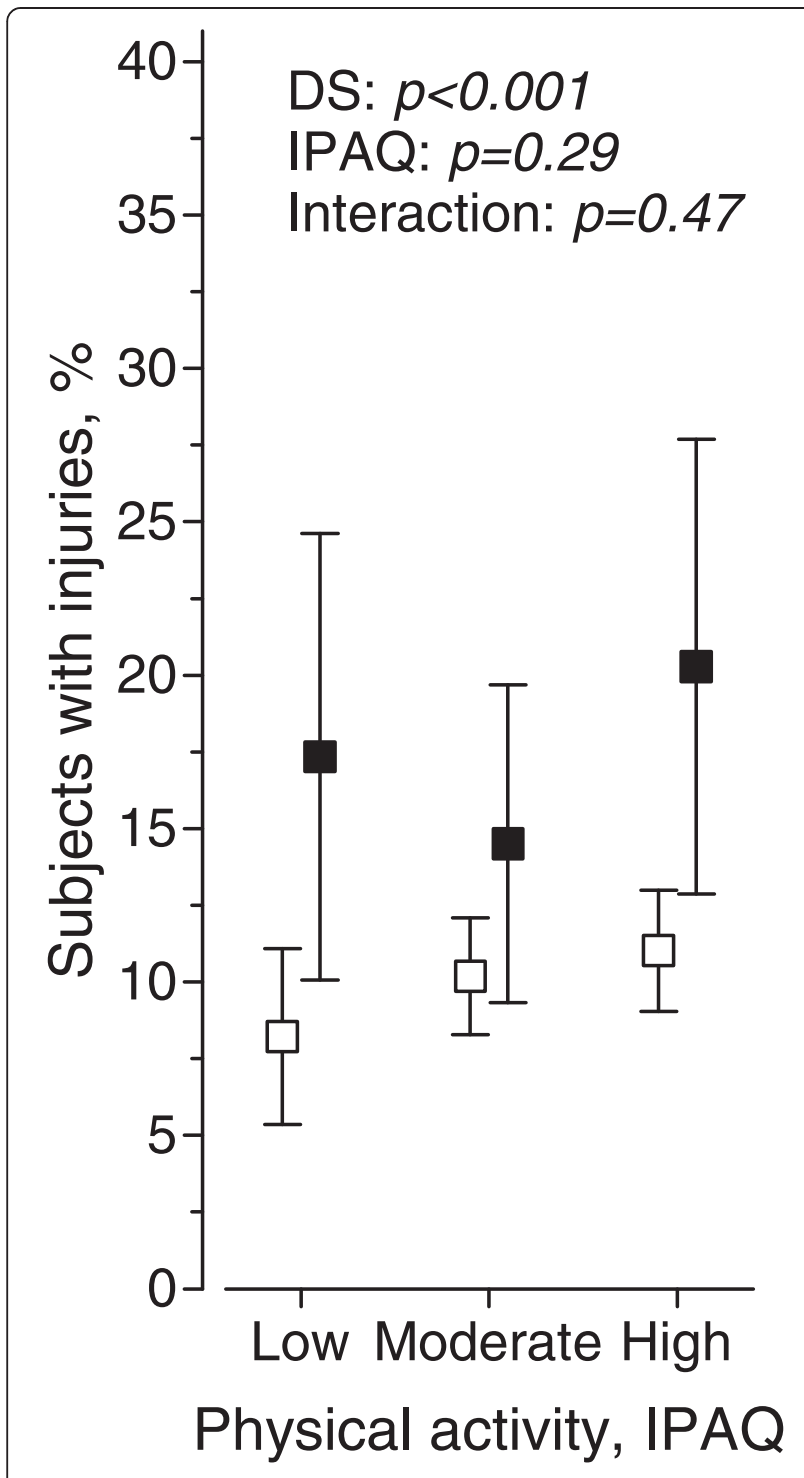

Figure 1 Age- and gender-adjusted percentage of subjects with unintentional injuries in physical activity categories according to depressive symptoms (DS). Percentages with 95\% confidence intervals in participants with (black square) or without (open square) depressive symptoms are shown

other leisure-time unintentional injuries, which were the most common injuries identified in this study.

Reasons behind the relationship between DS and unintentional injuries can be speculated. In the analysis variety of known confounders was controlled including antidepressant use. Most of the previous studies examining injuries and mental health have reported antidepressant medication to be a risk factor for injuries [28,29], while the results of this study were not similar. In addition, Tiesman et al. found that DS are a risk factor for injury, regardless of the use of antidepressants [4]. Hence, some alternative explanations for the relationship may be found which have, however, not been examined
Table 2 Number of subjects with different causes of unintentional injuries according to depressive symptoms (DS)

\begin{tabular}{lll}
\hline & DS $\mathbf{n}(\%)$ & No DS n (\%) \\
\hline Cause of injury & & \\
Traffic injury & $12(15)$ & $32(12)$ \\
Home injury & $33(42)$ & $104(39)$ \\
Sports injury & $8(10)$ & $50(19)$ \\
Other leisure-time injury & $26(33)$ & $81(30)$ \\
\hline
\end{tabular}

in this study. Perhaps increased daytime sleepiness and a lack of concentration among those with DS may act as connecting factors [30].

Moreover, some differences in clinical factors were found between participants with and without unintentional injuries in addition to DS. Those with unintentional injuries reported higher prevalence of somatic diseases and worse functional ability as well. These factors reached statistical significance in univariate analysis, and functional ability and musculoskeletal diseases were related to unintentional injuries in multivariate analysis as well. Functional ability worsens because of musculoskeletal diseases [31] and likely due to other somatic diseases as well. Therefore improving functioning could have positive impact on injury prevention. Improvement in functioning might be remarkable with respect to injury prevention planning and primary care settings [32].

In the univariate analysis, older age and higher BMI proved to be significant demographic factors related to unintentional injuries, as found in earlier research $[7,33]$. However, in contrast to previous studies male gender, years of education, and alcohol use did not seem related to the unintentional injury rate in this population-based study $[2,4,7]$. Reasons behind why alcohol use was not related to unintentional injuries can be speculated. Firstly, the participation rate of heavy drinkers was likely to have been low and, furthermore, the respondents may have underestimated their alcohol consumption to provide socially desirable answers.

The most common injuries appeared to be home and other leisure-time unintentional injuries. This finding is in line with a previous report from Finland [34]. Sports and traffic unintentional injuries seemed to play a minor role in the present population-based study. We found that only a minority of all unintentional injuries were sports-related both among those with DS (10\%) and without DS (19\%). Sports-related injuries may be more likely to occur among physically active persons [35]. This probably explains the difference in the prevalence of sports-related injuries between those with and without DS.

Most of the earlier studies about physical activity as an underlying factor in injuries have focused on activityspecific injuries by comparing injury risks within specific 
Table 3 Univariate and multivariate stepwise logistic regression models for unintentional injuries

\begin{tabular}{|c|c|c|c|c|}
\hline & \multicolumn{2}{|l|}{ Univariate } & \multicolumn{2}{|l|}{ Multivariate $^{a}$} \\
\hline & OR $(95 \% \mathrm{Cl})$ & $p$-value & OR (95\% Cl) & $p$-value \\
\hline Age & $1.02(1.00$ to 1.03$)$ & 0.034 & & \\
\hline Male gender & 1.09 (0.86 to 1.38$)$ & 0.49 & & \\
\hline Body mass index & 1.03 (1.00 to 1.05$)$ & 0.032 & & \\
\hline Education years & $1.00(0.97$ to 1.03$)$ & 0.93 & & \\
\hline Depressive symptoms & 1.80 (1.34 to 2.43$)$ & $<0.001$ & $1.52(1.11$ to 2.10$)$ & 0.010 \\
\hline Use of antidepressants & 1.24 (0.76 to 2.02$)$ & 0.38 & & \\
\hline Functional ability & 2.31 (1.62 to 3.30$)$ & $<0.001$ & 1.74 (1.15 to 2.61$)$ & 0.008 \\
\hline Cardiovascular diseases & 1.50 (1.18 to 1.92$)$ & $<0.001$ & & \\
\hline Respiratory diseases & 1.59 (1.09 to 2.33$)$ & 0.016 & & \\
\hline Musculoskeletal diseases & 1.63 (1.27 to 2.08$)$ & $<0.001$ & 1.38 (1.06 to 1.80$)$ & 0.018 \\
\hline IPAQ & & $0.27^{\mathrm{b}}$ & & \\
\hline$<600$ & 1 (reference) & & & \\
\hline 600-2999 & $1.06(0.74$ to 1.51$)$ & & & \\
\hline$\geq 3000$ & 1.19 (0.84 to 1.70$)$ & & & \\
\hline Alcohol use & & $0.24^{\mathrm{b}}$ & & \\
\hline Never & 1 (reference) & & & \\
\hline Occasionally & $1.19(0.91$ to 1.55$)$ & & & \\
\hline At least once a month & 1.15 (0.78 to 1.68$)$ & & & \\
\hline At least once a week & 1.24 (0.74 to 2.08$)$ & & & \\
\hline
\end{tabular}

OR, odds ration; $\mathrm{Cl}$, confidence interval; IPAQ, International Physical Activity Questionnaire.

a: Forward stepwise selection. Out of all variables used in univariate model only those are shown which remined stististically significant. (probability for entry 0.05 ). b: $p$ for linearity.

sports or activities [11,35-37]. However, in this populationbased study PA was not among the factors that explain unintentional injuries, even in the univariate analysis. The present findings seem to be consistent with other research, which found no association between leisuretime physical activity and overall injuries [35]. The risk of activity-related injury has shown to be greater for physically active people, whereas the risk of other types of injuries has shown to be greater for sedentary people [35]. Perhaps different results would be obtained if we had studied a younger population whose physical activity behaviors would likely have been different. Furthermore, there was no difference in the prevalence of unintentional injuries in the high, moderate, or low PA categories in groups according DS.

On the other hand, PA could be beneficial with respect to injury prevention, as it has proven to be strictly related to functional ability $[12,13]$. PA contributes favorably to balance, muscle strength, and neuromuscular control [32], which in turn improves functional ability. A recently published injury prevention report encourages adults to maintain and increase their sporting and physical activity behaviors and suggests taking up activities appropriate for their age and individual level of fitness and experience [38]. Furthermore, the report emphasizes the importance of sufficient PA among elderly people for maintaining independency and reducing falls and fractures [38].

In the present study, those with DS had higher amounts of activity loss days after unintentional injuries. Wan et al. also reported longer lengths of hospital stay in mentally ill participants after unintentional injury [39]. One explanation behind this longer recovery period might be that the presence of DS affects the perceived disability by lowering the sense of complete recovery after the injury [4]. Another explanation may be the lower functional ability among those with DS reported in this study because functional ability has proved to be highly predictive for recovery after injury [40].

Some limitations have to be acknowledged in this study. Due to participation rate of $64 \%$ in this study with a random sample of the population, we cannot exclude the effect of selection bias on the results. On the other hand, those who did not participate were younger, and thus cannot directly be assumed that they have worse overall health status. Further females who are stated to have higher prevalence of DS were more likely to participate in the study than males. The information about injuries was collected retrospectively; as a result, participants do not necessarily remember all the injuries they had during the 
previous 12 months. People tend to forget about 30\% of their injuries over the course of a year [41]. However, because we limited the unintentional injuries only to those needing medical attention, the possibility of this source of error becomes minimal. The assessment of DS and total PA relied on self-reported questionnaires, which have the potential for error in judgment, recall difficulties, misinterpretation of questions, and to elicit socially desirable responses. However, both the BDI and IPAQ questionnaires are validated and widely used in these areas, which also allows the comparison of the results with other studies $[21,42]$. The main strength is the large populationbased data on males and females. However, because of a lower age limit of 45 years in this study, the results cannot be generalized to younger individuals. Further, the present cross-sectional design does not allow drawing of a causal conclusion. Longitudinal studies should be done to assess the prospective relationships between PA, DS and unintentional injuries.

\section{Conclusions}

The main result of this study showed that depressive symptoms were related to a higher prevalence of unintentional injuries and prolonged activity-loss after injury. In addition, lower functional ability and musculoskeletal diseases were significantly related to the occurrence of unintentional injuries, whereas physical activity level was not. These results underline the importance of injury prevention, particularly among those who have DS and additional risk factors by increasing safety at home and during leisure-time activities.

\begin{abstract}
Abbreviations
PA: Physical activity; DS: Depressive symptoms; FIN-D2D: The Finnish type 2 diabetes survey; MONICA: Multinational monitoring of trends and determinants in cardiovascular disease; BMI: Body mass index; IPAQ: International Physical Activity Questionnaire; MET: Metabolic equivalent; BDI: Beck depression inventory; SD: Standard deviations; Cl: Confidence intervals.

\section{Competing interests}

Dr. Kampman has been acting as a consulting expert for Janssen, Pfizer and Lundbeck. All other authors declare that they have no conflicts of interest to report.

\section{Authors' contributions}

$\mathrm{KK}, \mathrm{AH}, \mathrm{HJK}$, and MV participated in designing the study and drafted the manuscript. HK and SJ participated in designing the study, performed the statistical analysis and drafted the manuscript. All authors have made substantial contributions to conception and design, or acquisition of the data, participated in drafting of the article or critical revision for important intellectual content. All authors read and approved the final manuscript.
\end{abstract}

\section{Acknowledgments}

FIN-D2D, the implementation project of the national program for the prevention of type 2 diabetes, was conducted in five Finnish hospital districts covering a population of 1.5 million during the years 2003-200. The main objective was to build up a nationwide program for the prevention of type 2 diabetes. FIN-D2D was initiated by the Finnish Diabetes Association with five Finnish hospital districts in collaboration with the National Institute for Health and Welfare and the Ministry of Social Affairs and Health in cooperation with the FIN-D2D Study Group. The specific aims were to improve screening of people at risk for diabetes and detection of undiagnosed diabetes. Furthermore, intensified interventions of high-risk individuals were developed and tested as part of normal clinical practice in primary health care.

FIN-D2D was supported by financing from the hospital districts of Pirkanmaa, Southern Ostrobothnia, North Ostrobothnia, Central Finland and Northern Savo, the Finnish National Public Health Institute, the Finnish Diabetes Association, the Ministry of Social Affairs and Health in Finland and Finland's Slottery Machine Association, the Academy of Finland (grant number 129293), and Commission of the European Communities, Directorate CPublic Health (grant agreement number 2004310) in co-operation with the FIN-D2D Study Group and the Steering Committee: Huttunen J, Kesäniemi A, Kiuru S, Niskanen L, Oksa H, Pihlajamäki J, Puolakka J, Puska P, Saaristo T, Vanhala $\mathrm{M}$ and Uusitupa M. This work was supported by research grants from the University of Jyväskylä, Juho Vainio Foundation and the Finnish Cultural Foundation.

\section{Author details}

'Department of Health Sciences, University of Jyväskylä, PL 35, Jyväskylä $\mathrm{Fl}-40014$, Finland. ${ }^{2}$ Department of Physical and Rehabilitation Medicine, Central Finland Central Hospital, Keskussairaalantie 19, FI-40620 Jyväskylä, Finland. ${ }^{3}$ Department of Psychiatry, Kuopio University Hospital, Kuopio, Finaland. ${ }^{4}$ University of Eastern Finland, Kuopio Fl-70210, Finland. ${ }^{5}$ Unit of Family Practice, Central Finland Central Hospital, Keskussairaalantie 19, FI-40620 Jyväskylä, Finland. ${ }^{6}$ Unit of Primary Health Care, Kuopio University Hospital, PO Box 1777, Kuopio Fl-70211, Finland. ${ }^{7}$ Medcare foundation, Jyväskylä, Finland. ${ }^{8}$ Chronic Disease Epidemiology and Prevention Unit, National Institute for Health and Welfare, P.O. Box 30, Helsinki FI-00271, Finland. ${ }^{9}$ Unit of Primary Health Care, University of Eastern Finland, PO Box 1627, Kuopio Campus Fl-70211, Finland. ${ }^{10}$ Department of Psychiatry, Seinäjoki Hospital District and Medical School, University of Tampere, Tampere FI-33014, Finland. ${ }^{11}$ Tampere University Hospital, Teiskontie 35, Tampere Fl-33521, Finland.

Received: 3 April 2012 Accepted: 25 June 2012

Published: 10 July 2012

\section{References}

1. Nordstrom DL, Zwerling C, Stromquist AM, Burmeister LF, Merchant JA: Epidemiology of unintentional adult injury in a rural population. J Trauma 2001, 51:758-766.

2. Patten SB, Williams JV, Lavorato DH, Eliasziw M: Major depression and injury risk. Can J Psychiatry 2010, 55:313-318.

3. Poole GV, Lewis JL, Devidas M, Hauser CJ, Martin RW, Thomae KR: Psychopathologic risk factors for intentional and nonintentional injury. J Trauma 1997, 42:711-715.

4. Tiesman HM, Peek-Asa C, Whitten P, Sprince NL, Stromquist A, Zwerling C: Depressive symptoms as a risk factor for unintentional injury: a cohort study in a rural county. Inj Prev 2006, 12:172-177.

5. Scaf-Klomp W, Sanderman R, Ormel J, Kempen GIJM: Depression in older people after fall-related injuries: a prospective study. Age and Ageing 2003, 32:88-94.

6. Vikhireva O, Pikhart H, Pajak A, Kubinova R, Malyutina S, Peasey A, ToporMadry R, Nikitin Y, Marmot M, Bobak M: Non-fatal injuries in three Central and Eastern European urban population samples: the HAPIEE study. The Eur J Publ Health 2010, 20:695-701.

7. Sethi D, Racioppi F, Baumgarten I, Bertollini R: Reducing inequalities from injuries in Europe. Lancet 2006, 368:2243-2250.

8. Yearbook of Alcohol and Drug Statistics 2010: Official Statistics of Finland, Social Protection. Helsinki: National Institute for Health and Welfare; 2010.

9. Kannus P, Sievänen $H$, Palvanen $M$, Järvinen T, Parkkari J: Prevention of falls and consequent injuries in elderly people. Lancet 2005, 366:1885-1893.

10. Warburton DE, Nicol CW, Bredin SS: Health benefits of physical activity: the evidence. CMAJ 2006, 174:801-809.

11. Hootman JM, Macera CA, Ainsworth BE, Martin M, Addy CL, Blair SN: Association among physical activity level, cardiorespiratory fitness, and risk of musculoskeletal injury. Am J Epidemiol 2001, 154:251-258. 
12. Hillsdon MM, Brunner EJ, Guralnik JM, Marmot MG: Prospective study of physical activity and physical function in early old age. Am J Prev Med 2005, 28:245-250

13. Manini TM, Pahor M: Physical activity and maintaining physical function in older adults. British J Sports Med 2009, 43:28-31.

14. Saaristo T, Peltonen M, Keinänen-Kiukaanniemi S, Vanhala M, Saltevo J, Niskanen L, Oksa H, Korpi-Hyövälti E, Tuomilehto J: FIN-D2D Study Group: National type 2 diabetes prevention programme in Finland: FIN-D2D. Int J Circumpolar Health 2007, 66:101-112.

15. Saaristo TE, Barengo NC, Korpi-Hyovalti E, Oksa H, Puolijoki H, Saltevo JT, Vanhala M, Sundvall J, Saarikoski L, Peltonen M, Tuomilehto J: High prevalence of obesity, central obesity and abnormal glucose tolerance in the middle-aged Finnish population. BMC Publ Health 2008, 8:423.

16. World Health Organization: The World Health Organization MONICA Project (monitoring trends and determinants in cardiovascular disease): a major international collaboration. WHO MONICA Project Principal Investigators. J Clin Epidemio/ 1988, 41:105-114.

17. Katz S, Downs TD, Cash HR, Grotz RC: Progress in development of the index of ADL. Gerontologist 1970, 10:20-30.

18. Katz S, Ford AB, Moskowitz RW, Jackson BA, Jaffe MW: Studies of Illness in the Aged. the Index of Adl: a Standardized Measure of Biological and Psychosocial Function. JAMA 1963, 185:914-919.

19. Lawton MP, Brody EM: Assessment of older people: self-maintaining and instrumental activities of daily living. Gerontologist 1969, 9:179-186.

20. McWhinnie JR: Disability assessment in population surveys: results of the O.E.C.D. Common Development Effort. Rev Epidemiol Sante Publique 1981, 29:413-419.

21. Bauman A, Bull F, Chey T, Craig CL, Ainsworth BE, Sallis JF, Bowles HR, Hagstromer M, Sjostrom M, Pratt M: The IPS Group: The International Prevalence Study on Physical Activity: results from 20 countries. Int J Behav Nutr Phys Act 2009, 6:21.

22. Craig $C L$, Marshall AL, Sjostrom M, Bauman AE, Booth ML, Ainsworth BE, Pratt M, Ekelund U, Yngve A, Sallis JF, Oja P: International physical activity questionnaire: 12-country reliability and validity. Med Sci Sports Exerc 2003, 35:1381-1395.

23. Hallal PC, Victora CG: Reliability and validity of the International Physical Activity Questionnaire (IPAQ). Med Sci Sports Exerc 2004, 36:556.

24. Fogelholm M, Malmberg J, Suni J, Santtila M, Kyrolainen H, Mantysaari M, Oja P: International physical activity questionnaire: validity against fitness. Med Sci Sports Exerc 2006, 38:753-760.

25. Beck AT, Ward CH, Mendelson M, Mock J, Erbaugh J: An inventory for measuring depression. Arch Gen Psychiatry 1961, 4:561-571.

26. Koponen H, Jokelainen J, Keinanen-Kiukaanniemi S, Kumpusalo E, Vanhala M: Metabolic syndrome predisposes to depressive symptoms: a population-based 7-year follow-up study. J Clin Psychiatry 2008, 69:178-182.

27. Väänänen $A$, Buunk $A P$, Kivimäki M, Vahtera J, Koskenvuo $M$ : Change in reciprocity as a predictor of depressive symptoms: a prospective cohort study of Finnish women and men. Soc Sci Med 2008, 67:1907-1916.

28. Modén B, Ohlsson H, Merlo J, Rosvall M: Psychotropic drugs and accidents in Scania. The European Journal of Public Health: Sweden; 2011, Sep 6 [Epub ahead of print].

29. Woolcott JC, Richardson KJ, Wiens MO, Patel B, Marin J, Khan KM, Marra CA: Meta-analysis of the impact of 9 medication classes on falls in elderly persons. Arch Intern Med 2009, 169:1952-1960.

30. Maglione JE, Ancoli-Israel S, Peters KW, Paudel ML, Yaffe K, Ensrud KE, Stone $\mathrm{KL}$ : Depressive symptoms and subjective and objective sleep in community-dwelling older women. J Am Geriatr Soc 2012, 60:635-643.

31. Roux CH, Guillemin F, Boini S, Longuetaud F, Arnault N, Hercberg S, Briancon S: Impact of musculoskeletal disorders on quality of life: an inception cohort study. Ann Rheum Dis 2005, 64:606-611.

32. Haskell WL, Lee IM, Pate RR, Powell KE, Blair SN, Franklin BA, Macera CA, Heath GW, Thompson PD, Bauman A: American College of Sports Medicine, American Heart Association: Physical activity and public health: updated recommendation for adults from the American College of Sports Medicine and the American Heart Association. Circulation 2007, 116:1081-1093.

33. Xiang H, Smith GA, Wilkins JR III, Chen G, Hostetler SG, Stallones L: Obesity and risk of nonfatal unintentional injuries. Am J Prev Med 2005, 29:41-45.

34. Ministry of Social Affairs and Health: Safe at home and at leisure. Target programme for the prevention of home and leisure accident injuries for
2007-2012. Helsinki: Publications of the Ministry of Social Affairs and Health; 2006:20-21.

35. Carlson SA, Hootman JM, Powell KE, Macera CA, Heath GW, Gilchrist J, Kimsey J, Dexter C, Kohl HW III: Self-reported injury and physical activity levels: United States 2000 to 2002. Ann Epidemiol 2006, 16:712-719.

36. Parkkari J, Kannus P, Natri A, Lapinleimu I, Palvanen M, Heiskanen M, Vuori I, Järvinen M: Active living and injury risk. Int J Sports Med 2004, 25:209-216.

37. Powell KE, Heath GW, Kresnow MJ, Sacks JJ, Branche CM: Injury rates from walking, gardening, weightlifting, outdoor bicycling, and aerobics. Med Sci Sports Exerc 1998, 30:1246-1249.

38. Martin-Diener E, Brügger O, Martin B: Physical activity promotion and injury prevention: relationship in sports and other forms of physical activity. Berne: bfu - Swiss Council for Accident Prevention 2010, bfu-report no. 64. ISBN 978-3-908192-38-1.

39. Wan JJ, Morabito DJ, Khaw L, Knudson MM, Dicker RA: Mental illness as an independent risk factor for unintentional injury and injury recidivism. J Trauma 2006, 61:1299-1304.

40. Kempen Gl, Sanderman R, Scaf-Klomp W, Ormel J: The role of depressive symptoms in recovery from injuries to the extremities in older persons. A prospective study. Int J Geriatr Psychiatry 2003, 18:14-22.

41. Elander J, West R, French D: Behavioral correlates of individual differences in road-traffic crash risk: an examination method and findings. Psychol Bull 1993, 113:279-294

42. Nuevo R, Dunn G, Dowrick C, Vazquez-Barquero JL, Casey P, Dalgard OS, Lehtinen V, Ayuso-Mateos JL: Cross-cultural equivalence of the Beck Depression Inventory: a five-country analysis from the ODIN study. J Affect Disord 2009, 114:156-162.

doi:10.1186/1471-2458-12-516

Cite this article as: Korniloff et al: Relationships between depressive symptoms and self-reported unintentional injuries: the cross-sectional population-based FIN-D2D survey. BMC Public Health 2012 12:516.

\section{Submit your next manuscript to BioMed Central and take full advantage of:}

- Convenient online submission

- Thorough peer review

- No space constraints or color figure charges

- Immediate publication on acceptance

- Inclusion in PubMed, CAS, Scopus and Google Scholar

- Research which is freely available for redistribution 